\title{
One minute of circulatory arrest for acute type A aortic dissection -------- a simple operation for acute type $A$ aortic dissection (AAAD)
}

Detian Jiang ${ }^{1}$, Yufeng Huo ${ }^{1}$, Yimin Liu' ${ }^{1}$, Yan Wang ${ }^{1}$, Jinfeng Zhou' ${ }^{1}$ Xiangfei Sun², Fen Zhao ${ }^{1}$, Yonghai Du' Songxiong $\mathrm{He}^{1}$, Chao Liu ${ }^{1}$ and Wenyu Sun ${ }^{1 *}$

\begin{abstract}
Background: Sun's procedure is currently recognized as the standard procedure for acute type A aortic dissection (AAAD). But the operation istoo difficult for beginners. We hope to reduce the difficulty and complications of this operation.

Methods: The aortic arch was immediately cross-clamped after the stented graft was inserted into the distal aorta. Thereafter, the lower-body perfusion was restored. Then, anastomosis was performed between the proximal stent graft and the distal 4-branched Dacron graft. The other arteries were anastomosed to the arched branch of the 4branched graft.

Results: The cardiopulmonary bypass (CPB) time was (207 \pm 52 ) min, and the aortic cross-clamp time was (114 \pm 39 ) min. The circulatory arrest time was $(38 \pm 16) \mathrm{sec}$. One patient $(4 \%)$ died. The incidence of complications was stroke (4\%), renal dysfunction requiring dialysis (4\%), prolonged intubation(12\%).

Conclusions: The time of circulatory arrest in this operation is less than 1 min, which can avoid the complications caused by DHCA and decrease risk of bleeding and complexity by shifting anastomosis more proximally. The effect of our operation is similar to and even better than that of Sun's procedure. It does not even require relatively advanced skill, much experience and excellent psychological quality, especially suitable for beginners.
\end{abstract}

Keywords: Circulatory arrest, Acute type a aortic dissection, Operation, Sun's procedure, One minute

\section{Background}

Acute type A aortic dissection (AAAD) remains one of the most challenging diseases for cardiothoracic surgeons. In spite of technical improvements, the perioperative mortality rate is stillvery high. In the early stage of AAAD, the mortality rate increases by approximately $1 \%$ per hour [1-3]. Surgery is the most effective treatment.

\footnotetext{
* Correspondence: sdsurgeon@163.com

'Department of Cardiovascular Surgery, Qilu Hospital of Shandong University, Qingdao 266000, China

Full list of author information is available at the end of the article
}

At present, the most common surgical methods for the treatment of AAAD are Sun's procedure and hybrid operations [4]. Sun's procedure is widely used because of its advanced techniques and good results,while it requires deep hypothermic circulatory arrest (DHCA). Hybrid surgeries can avoid DHCA, but they have more frequent long-term complications. We hope to reduce the difficulty of this operation on the basis of ensuringsurgical outcome. Our center tried a variety of surgical methods for the treatment of AAAD. At last,we coined one surgery which is based on Sun's procedure and the 
idea of debranching. The time of circulatory arrest needed during this surgery is only $1 \mathrm{~min}$.

Herein, we give a report incorporating 25 patients who were treated with this operation between January 2017 and December 2018, retrospectively.

\section{Patients and methods}

The retrospective study included 25 patients who underwent surgical treatment in Qilu Hospital of Shandong University between January 2017 and December 2018. All patients were diagnosed with AAAD by aortic computed tomography angiography (CTA)before the operation.

\section{Operative indications}

(1) type A dissections with the primary entry locating in the arch and descending aorta

(2) type A dissections severely involving the archvessels

(3) type A dissections with extensive intimal intussusception

(4) Marfan syndrome complicated with type Adissection

This study was approved by the Ethics Committee of Qilu Hospital of Shandong University. Their clinical data are summarized in Table 1.

\section{Surgical materials}

The materials were as same as which were used in Sun's procedure. The stented graft is $150 \mathrm{~mm}$ long and 28 to $32 \mathrm{~mm}$ in diameter. It consists of a Gianturco-type selfexpandable metallic stent (Microport Medical Corp) and a high-porosity woven Dacron graft (Intervascular OLP, Intervascular Inc). At each end, there is a10-mm-long stent-free sewing edge which could be clamped without affecting the overall performance of the stent $[5,6] .120$ $\mathrm{mm}$ stented grafts were used in some women who were

Table 1 Clinical Data

\begin{tabular}{lll}
\hline & Number & Mean \pm SD \\
\hline Sex M:F & $20: 5$ & \\
Age (years) & & $44 \pm 11$ \\
Hypertension & $21(84 \%)$ & \\
Marfan syndrome & $1(4 \%)$ & \\
Moderate to severe aortic regurgitation & $5(20 \%)$ \\
Cardiac tamponade & $1(4 \%)$ \\
Coronary ischemia & $2(8 \%)$ \\
Renal insufficiency & $3(12 \%)$ \\
Smoking, past or current & $17(68 \%)$ \\
Chest or abdominal pain & $25(100 \%)$ \\
Neurological symptoms & $4(16 \%)$ \\
Pulmonary disease & $2(8 \%)$ \\
\hline
\end{tabular}

especially short.. It was produced by Shanghai Minimally Invasive Company. (Fig. 1).

The 4-branched vascular graft (28 to $32 \mathrm{~mm}$ in diameter, $10 \times 8 \times 8 \times 10 \mathrm{~mm}$ ) was a product of Maquet Company [5, 6]. (Fig. 2).

During perioperative period,we treated the patients with oxygen,analgesia, maintain arterial pressure and heart rate. The operation was performed under general endotracheal anesthesia with continuous transesophageal echocardiography, cerebral oxygen saturation (rSO2), and arterial pressure monitoring.

\section{Operative technique}

After sternotomy, the patient was heparinized. A $8 \mathrm{~mm}$ (15 cm length) graft was end-to-side anastomosed to the left subclavian artery and the other end of this graft was tunneled via the second intercostal space into the mediastinum connected to the arterial tubes of the the cardiopulmonary bypass (CPB) machine. The femoral artery, innominate artery, left common carotid artery were cannulated with arterial catheters, which were connected to the arterial tubes of the CPB machine. Cooling was started after cannulation of the superior and inferior vena cava. The ascending aorta was cross-clamped at $30^{\circ} \mathrm{C}$ and the cardioplegic solution was usually perfused through a coronary sinus cannulation to arrest the heart. After the cardiac arrest, the aortic valve repair or replacement was performed if significant aortic valve insufficiency was identified. The ascending aorta was also replaced by the graft,which was anastomosed to the aortic sinotubular junction or the artificial valve ring. (Fig. 3a).

The innominate artery and the left common carotid artery were transected. Thereafter, the left subclavian

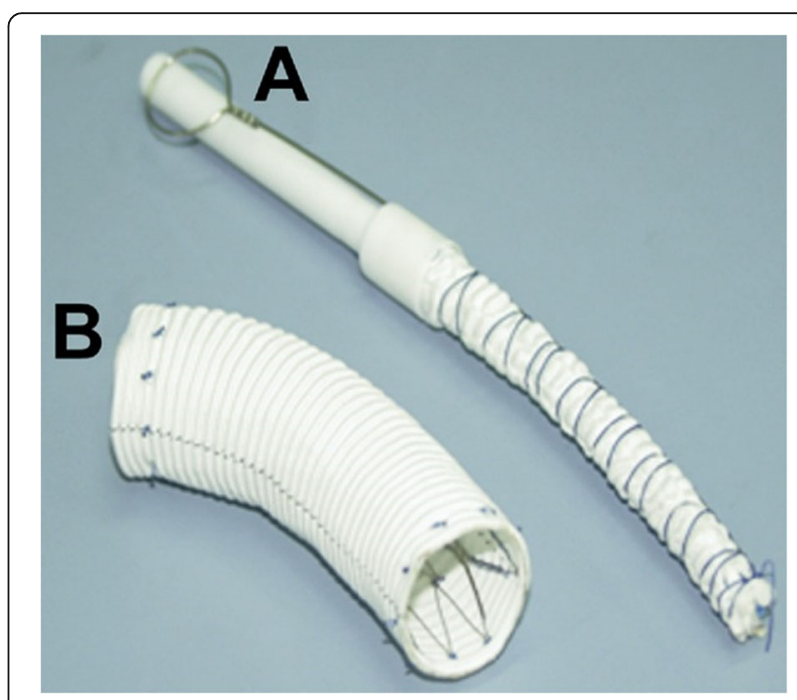

Fig. 1 The stented elephant trunk, Cronus ${ }^{\oplus}$, before (a) and after (b) implantation [6]. 


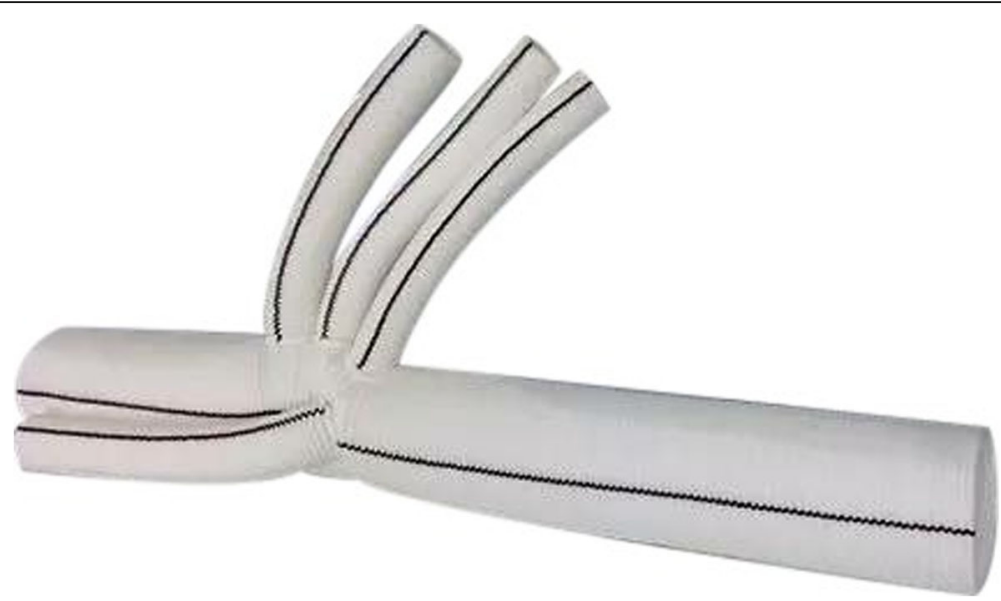

Fig. 2 The 4-branched vascular graft $(10 \times 8 \times 8 \times 10 \mathrm{~mm})$

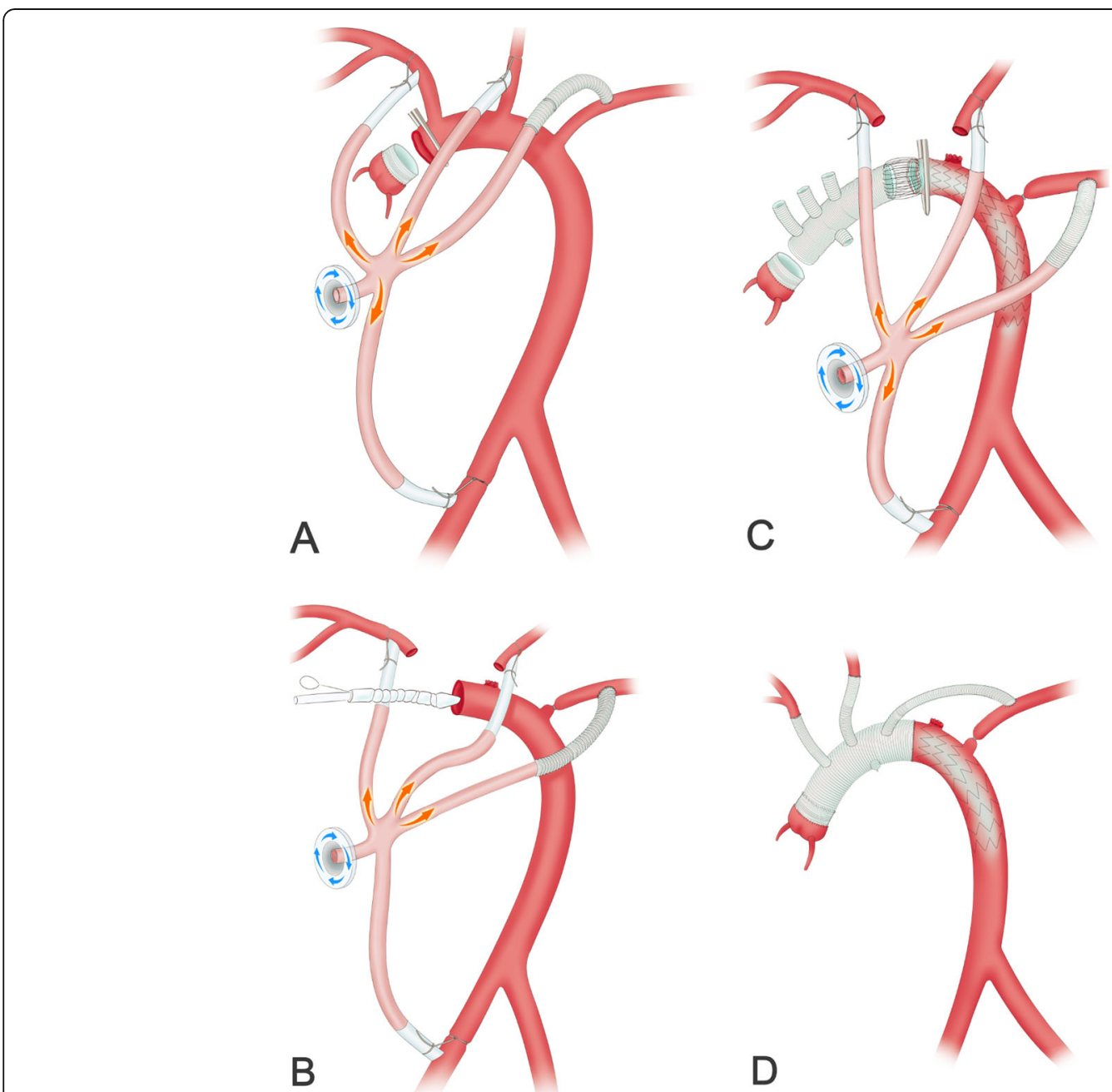

Fig. 3 The surgical procedure. a The aortic root was repaired after CPB was established. b The intraoperative stent was inserted into the distal aorta. $\mathbf{c}$ The anastomosis was performed between the proximal stent graft and the distal 4-branched graft after the aortic arch was cross-clamped. $\mathbf{d}$ The other arteries were anastomosed to the arched branch of the 4-branched graft 
artery was ligated proximally. The cross-clamp was moved to the distal aortic arch (between the innominate artery and the left common carotid artery), and the aortic arch was trimmed. Hypothermic circulatory arrest was started after removing the clamp. The intraoperative stent was inserted into the true lumen of the distal aorta in a bound, compressed state after the distal aorta was transected between the origin of the innominate artery and the left common carotid artery. Open the stent to support the inner wall of the aorta. (Fig. 3b).

The aortic arch was immediately cross-clamped after de-airing. Thereafter, the lower-body perfusion was restored. The self-aortic arch and the intraoperative stent's graft section were trimmed, and the sandwich treatment was performed. Then, anastomosis was performed between the proximal stent graft and the distal 4-branched Dacron graft. (Fig. 3c).

The previously placed graft on the root was retracted, stretched and measured to the site of proximal 4branched Dacron graft. Graft-to-graft anastomoses were performed. Finally, the innominate artery, the left common carotid artery and the $8 \mathrm{~mm}$ graft of left subclavian artery were anastomosed to the arched branch of the 4branched graft in proper sequence. (Fig. 3d).

The similarities and differences between our operation and Sun's procedure are summarized in Table 2.

\section{Results}

We compared our results with Sun's procedure completed at two of the best cardiac centers in China. In addition, a systematic review and meta-analysis was conducted. The results showed that the follow-up data in our operation were comparable or superior to the data in patients with Sun's procedure. The circulatory arrest time. lowest nasopharyngeal temperature and blood loss in our operation were less than that in Sun's procedure. And there were lower operative mortality rate and fewer complications in our operation.

Operative Data and are reported in Table 3.

Postoperative complications are reported in Table 4.

The follow-up for patients were from 18 months to 42 months. The interval of CTA was 6 months after the operation.

\section{Discussion}

Sun's procedure is currently recognized as the standard procedure for AAAD. The incidence of residual distal false lumen patency from Sun's procedure is less than $5 \%$, and the reoperation rate is less than $10 \%$ [10-12].

DHCA is indispensable for Sun's procedure. But DHCA may cause abdominal organ dysfunction such as ischemia-reperfusion injury, coagulation dysfunction, nervous system dysfunction and kidney dysfunction.

Table 2 The similarities and differences between our operation and Sun's procedure

\begin{tabular}{|c|c|c|}
\hline & Sun's procedure & Our operation \\
\hline Similarities & $\begin{array}{l}\text { operative Indications } \\
\text { surgical materials } \\
\text { anesthesia } \\
\text { cannulation of the vena cava } \\
\text { repair of aortic root }\end{array}$ & \\
\hline \multicolumn{3}{|l|}{ Differences } \\
\hline Incision & $\begin{array}{l}\text { median sternotomy } \\
\text { right infra-clavicular }\end{array}$ & $\begin{array}{l}\text { median sternotomy } \\
\text { left infra-clavicular } \\
\text { inferior inguinal ligament }\end{array}$ \\
\hline Artery perfusion & $\begin{array}{l}\text { right axillary artery } \\
\text { left common carotid artery }\end{array}$ & $\begin{array}{l}\text { femoral artery, } \\
\text { innominate artery, } \\
\text { left common carotid artery } \\
\text { left subclavian artery }\end{array}$ \\
\hline Left subclavian artery & $\begin{array}{l}\text { transected, } \\
\text { end-to-end anastomosed to } \\
\text { the arched branch of the } 4 \text { - } \\
\text { branched graft }\end{array}$ & $\begin{array}{l}\text { ligated, } \\
\text { A } 8 \mathrm{~mm} \text { graft was end-to-side anastomosed to the left sub- } \\
\text { clavian artery and the other end of this graft was tunneled via } \\
\text { the second intercostal space into the ediastinum connected to } \\
\text { the arched branch of the 4-branched graft }\end{array}$ \\
\hline Cerebral perfusion & selective & bilateral \\
\hline Temperature of circulatory arrest & deep hypothermia & $30^{\circ} \mathrm{C}$ \\
\hline Time of circulatory arrest & more than 20 min & less than $1 \mathrm{~min}$ \\
\hline $\begin{array}{l}\text { Lower-body perfusion when anastomosis was } \\
\text { performed between the proximal stent graft and } \\
\text { the distal 4-branched graft }\end{array}$ & No & $\begin{array}{l}\text { the aortic arch and stent graft were cross-clamped, lower- } \\
\text { body perfusion was restored by the femoral artery }\end{array}$ \\
\hline $\begin{array}{l}\text { Sit of anastomosis between the proximal stent } \\
\text { graft and the distal 4-branched graft }\end{array}$ & $\begin{array}{l}\text { descending aorta distally to } \\
\text { the origin of the native left } \\
\text { subclavian artery }\end{array}$ & $\begin{array}{l}\text { aortic arch between the innominate artery and the left } \\
\text { common carotid artery }\end{array}$ \\
\hline
\end{tabular}


Table 3 Operative Data

\begin{tabular}{|c|c|c|c|c|}
\hline & \multicolumn{2}{|c|}{ Our operation } & \multicolumn{2}{|c|}{ Sun's procedure } \\
\hline & Number & Mean SD & Number & Mean SD \\
\hline Bentall procedure & $1(4 \%)$ & & $\begin{array}{l}30 \%[7] \\
29 \%[8]\end{array}$ & \\
\hline Reconstruction of the sinus of Valsalva & $5(20 \%)$ & & $\begin{array}{l}17 \%[7] \\
33 \%[8]\end{array}$ & \\
\hline Coronary artery bypass graft & $1(4 \%)$ & & $9 \%[7]$ & \\
\hline CPB (min) & & $207 \pm 52$ & & $\begin{array}{l}201 \pm 51[7] \\
196 \pm 63[8]\end{array}$ \\
\hline Aortic cross-clamp time (min) & & $114 \pm 39$ & & $\begin{array}{l}111 \pm 31[7] \\
100 \pm 29[8]\end{array}$ \\
\hline Circulatory arrest (sec) & & $38 \pm 16$ & & $\begin{array}{l}1440 \pm 480[7] \\
1390 \pm 487[8]\end{array}$ \\
\hline Surgery duration (min) & & $463 \pm 136$ & & $408 \pm 125[8]$ \\
\hline Lowest nasopharyngeal temperature $\left({ }^{\circ} \mathrm{C}\right)$ & & 30 & & $\begin{array}{l}25[7] \\
20[8]\end{array}$ \\
\hline Blood loss during operation (mL) & & $841 \pm 85$ & & $947 \pm 773[8]$ \\
\hline \multicolumn{5}{|l|}{ Blood product use } \\
\hline Red cell $(U)$ & & $6.7 \pm 6.3$ & & $6.8 \pm 8.8[8]$ \\
\hline Fresh Frozen Plasma (mL) & & $845 \pm 692$ & & $873 \pm 1024[8]$ \\
\hline Platelet (U) & & $2.3 \pm 1.9$ & & $2.4 \pm 2.6[8]$ \\
\hline
\end{tabular}

Besides, the incidence of these dysfunction is positively correlated with the duration of DHCA [13-16].

Hybrid surgery can reduce the difficulty of the operation and recent complications by avoiding DHCA, but it also leads to a relatively high incidence of late complications [17, 18], due to its lack of one important step of Sun's procedure that the expandable stent graft can be firmly fixed to the distal 4-branched prosthetic graft using the suture line. One study reported that the incidence of late complications was up to $48 \%$, including delayed type I endoleak, stent migration, stent fracture and so on. Furthermore, $10 \%$ of the patients underwent late open surgery $[19,20]$.

In order to solve these problems, we coined a new surgery which is a combination of Sun's procedure and hybrid surgery. In this surgery, we proposed that we could use $1 \mathrm{~min}$ of circulatory arrest to place the expandable stent graft into the aorta. This amount of time is so short that there is no need for deep hypothermia.

The time that DHCA is safe is $30-40 \mathrm{~min}$; the shorter the time is, the better [21, 22]. If surgeons can not complete high-quality complex surgery as soon as

Table 4 Postoperative Complications

\begin{tabular}{|c|c|c|}
\hline Postoperative complications & Our operation & Sun's procedure \\
\hline In-hospital death & $1(4 \%)$ & $\begin{array}{l}7.8 \%[7] \\
10.7 \%[8] \\
8.6(7.0-10.2) \%[9]\end{array}$ \\
\hline Stroke & $1(4 \%)$ & $\begin{array}{l}4.4 \%[8] \\
3.7(2.1-5.7) \%[9]\end{array}$ \\
\hline Renal dysfunction requiring dialysis & $1(4 \%)$ & $\begin{array}{l}4.3 \%[7] \\
9.6 \%[8]\end{array}$ \\
\hline Prolonged intubation (including Tracheostomy) & $3(12 \%)$ & $17.1(10.9-24.4) \%[9]$ \\
\hline Recurrent nerve palsy & 0 & $1 \%[7]$ \\
\hline Paraplegia & 0 & $\begin{array}{l}1.8 \%[7] \\
4.4 \%[8] \\
1.95(1.04-3.12) \%[9]\end{array}$ \\
\hline Hepatic insufficiency & 0 & $31.4 \%[8]$ \\
\hline Reexploration for bleeding & 0 & $\begin{array}{l}2.5 \%[7] \\
3.7 \%[8]\end{array}$ \\
\hline
\end{tabular}


possible during safe operational time window, patients may be left with serious complications. So they need relatively advanced skill, much experience and excellent psychological quality.

On the contrary, a surgeon does not need to worry about the time of circulatory arrest in our surgery. Thus, it apparently reduces the psychological pressure on the surgeon, which is conducive to a better effect.

When the distal aortic arch is anastomosed, bilateral anterograde cerebral perfusion and retrograde femoral artery perfusion are adopted. There is theoretical possibility of retrograde tear of the dissection pseudolumen during retrograde femoral artery perfusion. However, some research shows that this approach is safe and reliable [23].

In Sun's procedure, it is difficult to handle the root of the left subclavian artery, and the recurrent laryngeal nerve can be easily injured. End-to-side anastomosis was performed between the graft and left subclavian artery via a left infraclavicular incision in our surgical procedure. During the operation, the left vertebral artery could be perfused continuously through the graft, which is helpful for protecting the brain and spinal cord. The distal anastomosis was located between the innominate artery and the left carotid artery, which was relatively simple and easy to be exposed. Then, sutures were placed, and the hemostasis was maintained. The risk of bleeding and recurrent laryngeal nerve injury was reduced. Since the three branches of the aortic arch were perfused continuously, they were anastomosed after the reconstruction of the aortic arch so that the length and location of the branches were easier to be adjusted, which further reduced the difficulty of the operation.

In the study, one patient experienced aggravation of renal damage from preoperative renal insufficiency to postoperative renal failure After treatment with continuous renal replacement therapy (CRRT), his renal function returned to be normal. No paraplegia, liver failure or other abdominal organ ischemia complications occurred in this study. The adoption of continuous perfusion of the subclavian artery and less than $1 \mathrm{~min}$ circulatory arrest reduced the risk of ischemia and ischemia reperfusion injury. Therefore, this approach is beneficial for the protection of the spinal cord and abdominal organs and allows for the possibility of reducing the incidence of related complications.

In addition, another advantage of our operation is that the location of anastomosis on the aorta is altered from the left subclavian artery to the innominate artery, which decreases the risk of bleeding and complexity by shifting anastomosis more proximally.

It is also one of the aprroaches to prevent DHCA that coda balloon or Foley's catheter is used to block descending thoracic aorta and then lower body can be perfused by femoral artery, which can also protect abdominal organs,which can also protect abdominal organs [24-26]. However, compared with our operation, there are some disadvantages, such as blood leakage around the balloon and unclear vision when the distal end is sutured. What's more, the anastomosis is still too far for the surgeon, which cannot reduce the difficulty of operation.

\section{Limitations}

The number of locations for anastomoses was more in this procedure than that in Sun's procedure; thus, the overall operation time of this operation was appropriately longer than that of Sun's procedure.

\section{Conclusions}

The time of circulatory arrest in this operation is less than $1 \mathrm{~min}$, which can avoid the complications caused by DHCA and decrease risk of bleeding and complexity by shifting anastomosis more proximally..The effect of our operation is similar to and even better than that of Sun's procedure. The most important is that this operation is much easier than Sun's procedure. To some extent, this procedure can be regarded as a simple version of Sun's procedure. It does not even require relatively advanced skill, much experience and excellent psychological quality, especially suitable for beginners.

\section{Abbreviations}

AAAD: Acute type A aortic dissection; CPB: Cardiopulmonary bypass; CTA: Computed tomography angiography; DHCA: Deep hypothermic circulatory arrest; CRRT: Continuous renal replacement therapy

\section{Acknowledgements \\ The authors are grateful to Ying He and Huiyun Li for proofreading this manuscript.}

\section{Authors' contributions}

Detian Jiang,Conceptualization, Writing - Original Draft. Yufeng Huo, Methodology. Yimin Liu, Methodology. Yan Wang, Investigation. Jinfeng Zhou, Investigation. Xiangfei Sun, Visualization, Data Curation. Fen Zhao, Data Curation. Yonghai Du, Data Curation. Songxiong He, Data Curation. Chao Liu, Data Curation. Wenyu Sun, Writing - Review \& Editing, Supervision, Project administration. All authors read and approved the final version of the manuscript.

\section{Funding}

No funding.

\section{Availability of data and materials}

The datasets during and/or analysed during the current study available from the corresponding author on reasonable request.

Ethics approval and consent to participate

Our research has been approved by the ethics committee of our hospital and the patients.

Consent for publication

Not applicable.

Competing interests

The authors declare that they have no competing interests. 


\section{Author details}

'Department of Cardiovascular Surgery, Qilu Hospital of Shandong University, Qingdao 266000, China. ${ }^{2}$ Department of Cardiovascular Surgery, Shandong Provincial Hospital Affiliated to Shandong University, Jinan, China.

Received: 7 July 2020 Accepted: 2 November 2020

Published online: 12 November 2020

\section{References}

1. Marullo AG, Bichi S, Pennetta RA, et al. Hybrid aortic arch debranching with staged endovascular completion in DeBakey type I aortic dissection. Ann Thorac Surg. 2010;90:1847-53.

2. Rampoldi V, Trimarchi S, Eagle KA, et al. Simple risk models to predict surgical mortality in acute type a aortic dissection: the international registry of acute aortic dissection score. Ann Thorac Surg. 2007;83(1):55-61.

3. Mussa FF, Horton JD, Moridzadeh R, et al. Acute aortic dissection and intramural hematoma: a systematic review. JAMA. 2016;316(7):754-63.

4. Appoo JJ. Strategies in the surgical treatment of type a aortic arch dissection. Ann Cardiothorac Surg. 2013;2:205-11.

5. Liu ZG, Sun LZ, Chang Q, et al. Should the "elephant trunk" be skeletonized? Total arch replacement combined with stented elephant trunk implantation for Stanford type a aortic dissection. J Thorac Cardiovasc Surg. 2006;131(1): 107-13.

6. Ma WG, Zheng J, Liu YM, Zhu JM, Sun LZ. Dr. Sun's procedure for type a aortic dissection: Total arch replacement using Tetrafurcate graft with stented elephant trunk implantation. Aorta (Stamford). 2013;1(1):59-64.

7. Ma WG, Zheng J, Dong SB, et al. Sun's procedure of total arch replacement using a tetrafurcated graft with stented elephant trunk implantation: analysis of early outcome in 398 patients with acute type a aortic dissection. Ann Cardiothorac Surg. 2013;2(5):621-8.

8. Zhang L, Yu C, Yang X, Sun X, Qiu J, Jiang W, et al. Hybrid and frozen elephant trunk for total arch replacement in DeBakey type I dissection. J Thorac Cardiovasc Surg. 2019;158:1285-92.

9. Smith HN, Boodhwani M, Ouzounian M, et al. Classification and outcomes of extended arch repair for acute type a aortic dissection: a systematic review and meta-analysis. Interact Cardiovasc Thorac Surg. 2017;24(3):450-9.

10. Sun L, Qi R, Zhu J, et al. Total arch replacement combined with stented elephant trunk implantation: a new"standard" therapy for type a dissection involving repair of the aortic arch? Circulation. 2011;123(9):971-8.

11. Ma WG, Zhang W, Wang LF, et al. Type a aortic dissection with arch entry tear: surgical experience in 104 patients over a 12-year period. J Thorac Cardiovasc Surg. 2016;151(6):1581-92.

12. Sun LZ, Ma WG, Zhu JM, et al. Sun's procedure for chronic type a aortic dissection: total arch replacement using a tetrafurcate graft with stented elephant trunk implantation. Ann Cardio Thorac Surg. 2013;2(5):665-6.

13. David TE, Armstrong $S$, Manlhiot $C$, et al. Long-term results of aortic root repair using the reimplantatation technique. J Thorac Cardiovasc Surg. 2013; 145(3 Suppl):S22-5.

14. Guan XL, Wang XL, Liu YY, et al. Changes in the hemostatic system of patients with acute aortic dissection undergoing aortic arch surgery. Ann Thorac Surg. 2016;101(3):945-51.

15. Parikh N, Trimarchi S, Gleason TG, et al. Changes in operative strategy for patients enrolled in the international registry of acute aortic dissection interventional cohort program. J Thorac Cardiovasc Surg. 2017;153(4):S74-9.

16. Shono Y, Akahoshi T, Mezuki S, et al. Clinical characteristics of type a acute aortic dissection with CNS symptom. Am J Emerg Med. 2017;35(12):1836-8.

17. Gao F, Chen J, Zeng Q. A modified and less invasive procedure in aortic arch replacement. Ann Thorac Surg. 2017;103:e203-6.

18. Kent WD, Herget EJ, Wong JK. Ascending, total arch, and descending thoracic aortic repair for acute DeBakey type I aortic dissection without circulatory arrest. Ann Thorac Surg. 2012;94:e59-61.

19. Gurupatham S, Qadura M, Andrinopoulos T, et al. Single Institution Experience with Hybrid Endovascular and Surgical Repairs Involving the Distal Aortic Arch. Ann Vasc Surg. 2019. https://doi.org/10.1016/j.avsg.2019. 03.008.

20. Joo HC, Youn YN, Kwon JH, et al. Late complications after hybrid aortic arch repair. J Vasc Surg. 2019. https://doi.org/10.1016/j.jvs.2019.01.058.

21. Moon MR, Sundt TM. Aortic arch aneurysms. Coron Artery Dis. 2002;13(7): 85-92.
22. Zierer A, Moon MR, Melby SJ, et al. Impact of perfusion strategy on neurologic recovery in acute type a aortic dissection. Ann Thorac Surg. 2007;83:2122-8

23. Klotz S, Heuermann K, Hanke T, et al. Outcome with peripheral versus central cannulation in acute type a dissection + . Interact Cardiovasc Thorac Surg. 2015;20:749-53.

24. Shao-peng ZHANG, Tong-yun CHEN, Nan JIANG, Qing-liang CHEN. Preliminary experience of selective antegrade cerebral perfusion and balloon catheter occlusion of descending aorta and moderate hypothermic circulatory arrest in aortic arch surgery of acute type a aortic dissection. Tianjin Med J. 2018:46(4):397-400

25. Takagi H, Mori Y, Iwata H, et al. Aortic balloon occlusion catheter with perfusion lumen for protection of lower body during distal anastomosis in aortic arch repair. J Thorac Cardiovasc Surg. 2002;123(5):1006-8.

26. Sun X, Guo H, Liu Y, Li Y. The aortic balloon occlusion technique in total arch replacement with frozen elephant trunk. Eur J Cardiothorac Surg. 2019; 55(6):1219-21.

\section{Publisher's Note}

Springer Nature remains neutral with regard to jurisdictional claims in published maps and institutional affiliations.

Ready to submit your research? Choose BMC and benefit from

- fast, convenient online submission

- thorough peer review by experienced researchers in your field

- rapid publication on acceptance

- support for research data, including large and complex data types

- gold Open Access which fosters wider collaboration and increased citations

- maximum visibility for your research: over $100 \mathrm{M}$ website views per year

At BMC, research is always in progress.

Learn more biomedcentral.com/submissions 